\title{
EXAMINATION OF SECONDARY SCHOOL TEACHERS SELF-ESTEEM AS A DETERMINANT OF THEIR MARITAL ADJUSTMENT IN ANAMBRA STATE
}

\author{
Chinyelu Nwokolo ${ }^{1}$,Ada Anyamene ${ }^{2}$, Edith Muojeke N. ${ }^{3}$ \\ ${ }^{1}$ Prof., Department of Guidance and Counselling, Faculty of Education, Nnamdi Azikiwe University, \\ Awka, Nigeria \\ ${ }^{2}$ Prof., Department of Guidance and Counselling,Faculty of Education, Nnamdi Azikiwe University, \\ Awka, Nigeria \\ ${ }^{3}$ PhD Research Scholar, Department of Guidance and Counselling,Faculty of Education, Nnamdi \\ Azikiwe University,Awka, Nigeria
}

Article DOI: https://doi.org/10.36713/epra7724 DOI No: 10.36713/epra7724

\begin{abstract}
Self-esteem as a psychosocial factor that is likely to foretell outcomes like academics, happiness, marital satisfaction and relationships is also a construct that could lead to marital success and happiness. This study examined secondary school teachers' self-esteem as a determinant of their marital adjustment in Anambra state. Three research questions were posed to guide the study while one null hypothesis was tested at a 0.05 level of significance. A correlational research design was adopted for the study. A sample size of 1,408 married teachers was drawn from a population of 6,987 married teachers. A multi-stage sampling procedure was followed in selecting the study sample. Two instruments: The marital Adjustment Scale (MAS), and Self- Esteem Scale (SES) were used for data collection. The instruments were duly validated by experts in measurement and evaluation and Guidance and Counselling. The reliability coefficient was established thus; 0.85 for the Self-esteem questionnaire, and 0.74 for the Marital Adjustment Questionnaire. Data was collected through a direct delivery approach and was analysed using SPSS version 23. Range of aggregate scores and Pearson correlation coefficients were used to answer research questions and while a t-test was used to test the hypotheses. Findings of the study showed among others there is a non-significant very low positive relationship existing between married teachers' Self-esteem and their marital adjustment in secondary schools in Anambra State. Based on the study's findings, it was suggested, among other things, that school Guidance Counsellors organise workshops and seminars for married teachers aimed at fostering healthy self-esteem for successful marital adjustment.
\end{abstract}

KEYWORDS: self-esteem, marital adjustment, married, teachers, school

\section{INTRODUCTION}

The union of couples who pledge a lifetime commitment, faithfulness, and fulfilment of responsibilities to each other, regardless of their profession or social status, forms the foundation of the family. It is a union that may include people from a variety of professions, including teachers. This connection, known as marriage, may form, break, and wither away since many married people may not have developed their personality mechanisms or shown suitable marital behaviour to deal adequately in the marriage. In such a case, they may have adjustment difficulties and may be unable to adjust to the demands of living together in such a setting.

When married teachers, for example, take on hard duties aimed at educational achievement and performance, their professional knowledge, abilities, and competences may be observed. However, when it comes to marriage, this is not always the case. A teacher's adjustment to the nature of her or his employment may be regarded as more essential than her or his adjustment to her or his marriage. As a result, friendship, agreement on core principles, loving closeness, accommodation, euphoria, and 
other elements may be absent between the instructor and the marital spouse.

Adjustment is a process of interacting with oneself and one's surroundings (Jaisri \&Joseph, 2013). During this process, one can either adapt to or change the surroundings. When this occurs in a marriage, it is referred to as marital adjustment. According to Sinha (2016), marital adjustment is the condition in which husband and wife have an overall feeling of contentment and satisfaction with their marriage and with each other. As Sinha pointed out, such feelings are dependent on the interaction between husband and wife satisfying each other's needs.

When married people are able to meet each other's requirements, it is probable that their marriage connection will expand and their compatibility between spouses will improve, allowing for marital adjustment. In this case, marital adjustment necessitates maturity in accepting and understanding the spouse's growth and development. If this progress is not completely experienced and realised, death in a married connection may be unavoidable. As a result, in the context of this study, marital adjustment is defined as the presence of such qualities in a marriage as the inclination to avoid or resolve disputes, couples' feelings of contentment with the marriage and with each other, and the sharing of resources and fulfilling of the marital expectation of the husband and wife.

According to the preceding definition, marital adjustment is a complicated phenomenon. Social scientists (for example, Spanier and Cole, 1976) have attempted to identify the traits that are most likely to ensure marital adjustment and marital satisfaction. The researchers found no key factors that strongly connect with marital satisfaction. Rather, the findings of research such as Vanover (2016) show that there are a variety of elements that contributes to marital success and satisfaction. According to Vanover, some of these characteristics include age at marriage, age disparities between spouses, educational level, duration of marriage, and personality factors such as self-esteem and selfconcept.

Self-esteem, a psychological construct that is likely to predict specific outcomes such as academics, happiness, and marital and relationship satisfaction, is one of the variables that lead to marital success and happiness. Farid and Akhtar (2013) define self-esteem as a positive or negative overall appraisal of oneself. It is the ability to accept, tolerate, respect, and be satisfied with oneself while eliminating feelings of superiority and perfection. It may also be defined as people's perceptions of themselves. Some people base their feelings about themselves on their self-awareness, self-expectation, and the exclusion of others.
According to Orth and Robins (2014), selfesteem is a component that impacts a person's cognition, interpretation, and emotional reactions, and it may be a determinant of the degree of stress of events. Self-esteem is a collection of results and ideas that have been declared in connection to a person and his surroundings. In other words, it is the citation of confirmation or lack of confirmation of a person's expectation of achievement, acceptance, and reaction to personal factors. According to this viewpoint, each individual has requirements that must be met in order to achieve an acceptable degree of health, and selfesteem is one of the basic human needs that is located in the emotional dimension.

According to Erol and Orth (2013), Oprisan and Critea (2012), and Sciangula and Morry (2009), self-esteem predicts better marital satisfaction. In their study on actor and partner impacts of selfesteem on relationship satisfaction, Erol and Orth (2013) discovered that self-esteem predicted relational happiness for both parties. According to Erol and Orth's findings, self-esteem is a component that can have a beneficial influence on life issues and tension among couples, and that a fall in self-esteem can create stress and unhappiness with life, which can lead to marital maladjustment.

According to the findings of research by Jaisri and Joseph (2013) and Muraru and Turliuc (2013), married people who are well-adjusted in their marriage have a stable existence, a satisfying marital life, a longer age, good health, and appropriate nutrition. Similarly, Zandipour and Momeni (2011) emphasised that marital adjustment has an impact on couples' contentment with life and income, academic performance, and job satisfaction. There is no doubt that a good marital adjustment may be the glee of marriage, and the occurrence of such glee would be the hallmark of a healthy marriage, in which both partners take care of each other's needs and understand the disparities between their perspectives and social reality. This might result in a healthy embedding between the spouses, which has the potential to influence their marital outcome as well as the perception of marriage in the society in which they reside.

Lack of marital adjustment may result in a situation in which a purportedly pleasant ambiance is replaced by turbulence in marriage. The repercussions are generally severe, resulting in marital instability, marriage separation, divorce, or even the couple's death. These might have significant consequences for students, families, children of marriage, society, and the nation. Understanding the link that exists between the personality variables (self-esteem and sexual behaviour) of married secondary school teachers in Anambra State may help to achieve early marital adjustment. This would 
most certainly aid in averting the difficulties that frequently follow poorly adjusted marriage.

\section{STATEMENT OF PROBLEM}

Adjusting to marital problems could be a significant component in building or weakening the foundation of their marriage for married secondary school teachers in Anambra State secondary schools. Self-esteem, for example, may be regarded as a significant criterion in adjusting with their marital spouses in accordance with each other's expectations. Self-esteem is a component that impacts a person's cognition, interpretation, and emotional reactions, and it can influence the magnitude of marital stress and adjustment. Despite the fact that several study attempts have been undertaken to explore factors that contribute to marital happiness, not much has been discovered among Anambra State teachers.

\subsection{Purpose of the Study}

The purpose of this study was to examine secondary school teachers' self-esteem as a determinant of their marital adjustment in Anambra state. Specifically, the study is set out to examined the:

1. Self-esteem distribution scores of married secondary school teachers in Anambra State

2. Marital adjustment distribution scores of married secondary school teachers in Anambra State.

3. Relationship between self-esteem and marital adjustment of married secondary school teachers in Anambra State.

\subsection{Significance of the Study}

The findings of this study will be beneficial to married teachers, practicing guidance counsellors, religious bodies and future researchers.

Findings of the study will be beneficial to the Guidance Counsellors. The findings will likely guide married teachers towards examining themselves to take decision that will make their marriages succeed by working on their self-esteem and sexual practices in order to avoiding conflict in their marriages, improve in their lapses towards their partners by practicing ways of achieving marital satisfaction and happiness in their marriages. This could be achieved when the content of this work is made available to the public or possibly through seminars and conferences. Through these processes, married could also learn about self-esteem and how it relates to the marital issues they are having.

\subsection{Research Questions}

The following research questions guided the study:

1. What are the self-esteem distribution scores of married secondary school teachers in Anambra State?
2. What are the marital adjustment distribution scores of married secondary school teachers in Anambra State?

3. What is the relationship between self-esteem and marital adjustment of married secondary school teachers in Anambra State?

\subsection{Hypothesis}

The following null hypothesis was formulated to guide the study and will be tested at 0.05 level of significance:

1. The relationship existing between selfesteem and marital adjustment of married secondary school teachers in Anambra State is not significant.

\section{MATERIALS AND METHODS}

This section is concerned with the procedures which the researcher used for the study.

\subsection{Research Design}

This study adopted a correlational research design. The design sought to determine the extent and direction of relationship between two or more variables.

\subsection{Research Setting}

The study was conducted in Onitsha Education Zone of Anambra State, located in the South East Geo-Political Zone of Nigeria. Anambra State was chosen for the study because the researcher is also a married teacher in one of the secondary schools, resides in the state and has observed that a good number of teachers in the secondary schools in the state seem to have issues of adjustment in their marriages.

\subsection{Participants}

The sample size of this study is 1,408 married public secondary school teachers. A multi-stage sampling technique was adopted in selecting the sample from a population of 6,887 married secondary school teachers in Anambra State.

\subsection{Instrument for Data Collection}

The questionnaire will be the research instrument that would be used by the researcher in eliciting response from the respondents in this study. The questionnaires include; Sexual Behaviour Scale (SBS) and Self- Esteem Scale (SES). Marital Adjustment Scale Questionnaire (MASQ) by Locke and Wallace (1959) was adapted and was used to assess the respondents (married teachers) marital adjustment. The instrument is a 15 -item scale used to ask questions related to their marriage.

Self- Esteem Scale (SES) was adapted from Rosenberge (1965) with little modification by the current researcher. The instrument has 21 structured 
items with a positive and negative scoring on four point rating scale, ranging from strongly agree to strongly disagree. The instruments were adapted and revalidated by experts to determine its face validity. A pilot study was conducted to determine the internal consistency reliability of the instrument. The resulted yielded a coefficient alpha of 0.85 for the Self-esteem questionnaire.

\subsection{Data Collection and Analysis}

The questionnaire instruments were directly administered on the respondents by the researcher and six research assistants. The data collected from the respondents were analysed using the Statistical Package for Social Sciences (SPSS). Research questions 1and 2 were answered using summated scores, research questions 3 was answered using Pearson Product Moment Correlation Coefficient while the null hypothesis was tested t-test of correlation.

\section{RESULTS}

Results from the field of study are presented in tables as follows:

\subsection{Research Question 1}

What are the self-esteem scores of married secondary school teachers in Anambra State?

Table 1: Distribution Scores of Married Secondary School Teachers in Anambra State Based on their self-esteem

\begin{tabular}{lccl}
\hline Range of scores & $\mathbf{N}$ & $\mathbf{\%}$ & Remarks \\
\hline $21.0-52.5$ & 655 & 57.4 & Healthy Self-esteem \\
$53.0-84.0$ & 487 & 42.6 & Low Self-esteem \\
\hline
\end{tabular}

Table 1 reveals that $655(57.4 \%)$ of the teachers in secondary schools with the scores ranging from 21.0 and 52.5 healthy self-esteem, while $487(42.6 \%)$ of the teachers who scored between 53

\subsection{Research Question 2}

What are the marital adjustment scores of married secondary school teachers in Anambra State?

Table 2: Distribution Scores of Secondary School Teachers in Anambra State Based on their marital adjustment ratings

\begin{tabular}{lcll}
\hline Range of scores & $\mathbf{N}$ & \multicolumn{1}{c}{$\%$} & Remarks \\
\hline $20.0-49.5$ & 78 & 6.8 & Marital Maladjustment \\
$50.0-80.0$ & 1064 & 93.2 & Marital Adjustment \\
\hline
\end{tabular}

Table 2 reveals that $78(6.8 \%)$ of the teachers in secondary schools with the scores ranging from 20.0 and 49.5 indicated they are maladjusted in their marriages, while $1064(93.2 \%)$ of the teachers who scored between 50.0 and 80.0 indicated marital adjustment.

Table 3: Pearson r on Self-Esteem and Marital Adjustment of Married Secondary School Teachers in Anambra State

$\begin{array}{lllll}\text { Variables } & \text { N } & \text { Self-esteem } \mathbf{r} & \text { Marital Adjustment } \mathbf{r} & \text { Remark }\end{array}$

\begin{tabular}{|c|c|c|}
\hline Self-esteem & 1142 & $\begin{array}{l}\text { Very Low } \\
\text { Positive Relationship }\end{array}$ \\
\hline Marital Adjustment & 0.035 & 1.00 \\
\hline $\begin{array}{l}\text { Table } 3 \mathrm{sh} \\
\text { positive relationshi } \\
\text { married teachers' } \\
\text { adjustment in second }\end{array}$ & $\begin{array}{l}\text { that there is a very low } \\
0.094 \text { existing between } \\
\text { esteem and their marital } \\
\text { chools in Anambra State. }\end{array}$ & $\begin{array}{l}\text { 4.4 Testing of Null Hypothesis } \\
\text { The relationship existing between self-esteem and } \\
\text { marital adjustment of married secondary school } \\
\text { teachers in Anambra State is not significant. }\end{array}$ \\
\hline
\end{tabular}

Table 4: t-test on the Relationship Existing between Self-Esteem and Marital Adjustment of Married

\begin{tabular}{lccccc} 
N & cal.r & df & Cal.t & Pvalue & Remark \\
\hline 1142 & 0.035 & 1139 & 1.072 & 0.284 & NS \\
\hline \multicolumn{7}{l}{ NS = Not Significant }
\end{tabular}


Table 4 shows that at 0.05 level of significance and $1139 \mathrm{df}$, the calculated t 1.072 have Pvalue 0.284 which is more than 0.05 which is the stipulated level of significance. So, the second null hypothesis is accepted. The relationship existing between self-esteem and marital adjustment of married secondary school teachers in Anambra State is not significant.

\section{DISCUSSION}

The findings of the study are discussed a follows:

5.1 Distribution Scores on Self-Esteem and Marital Adjustment of Married Secondary School Teachers in Anambra State

According to the study's findings, the majority of married secondary school teachers have healthy selfesteem. This means that married secondary school teachers in Anambra State regard themselves as better, more capable, and more valuable, and have a subjective appraisal of themselves as intrinsically positive in thought, feeling, and action. According to this, persons with good self-esteem may be less subject to social pressure to succeed at a higher level, more persistent, and capable of building satisfying relationships. According to the findings, the majority of married teachers in Anambra State secondary schools had good marital adjustment. This suggests that the majority of teachers are happy and satisfied with their marriages, and that they can adjust, adopt, or change individual and couple patterns of behaviour and interaction to attain optimum pleasure in the relationship.

Furthermore, the marriage most likely comprises a partnership in which the attitudes and actions of the married instructors create an environment that is highly favourable to the normal functioning of the couple's personality structures, particularly in the areas of personal interactions. In this instance, they may be able to reach an agreement on interests, objectives, and values that will allow them to demonstrate affection, share confidence, and have fewer or no severe complaints about their marriage.

\subsection{Self-Esteem as a determinant of Marital Adjustment of Married Secondary School Teachers in Anambra State}

According to the study's findings, there is a very weak positive association between married teachers' self-esteem and marital adjustment in secondary schools. The data also found that there is no significant association between self-esteem and marital adjustment among married secondary school teachers in Anambra State. This suggests that, while there is a low positive association between selfesteem and marital adjustment among married secondary school teachers, the link is not significant, indicating that self-esteem contributes little to school teachers' marital adjustment.

The findings are consistent with those of Onabamiro, Owoyele, and Elijah (2017), who investigated self-esteem, emotional intelligence, and coping skills as predictors of marital adjustment among couples in Abeokuta. The study's findings indicate a modest positive association between selfesteem and marital adjustment, as well as no significant relationship between self-esteem and marital adjustment. The finding is also similar with Johnson and Galambos' (2014) study, which found that self-esteem predicted the quality of a young adult's romantic relationship in a longitudinal study with a large sample of young adults. A similar study conducted by Schaffhuser, Wagner, Ludtke, and Allemand (2014), on the other hand, found no evidence for prospective effects between a person's self-esteem and relationship satisfaction.

A possible explanation for the above findings could be linked to the idea that self-esteem is often expressed as approval or disapproval and indicates the level to which people perceive themselves to be capable, relevant, useful, and deserving. The value one places on oneself, as well as the process by which individuals successfully adapt to the responsibilities and opportunities of marriage, can be beneficial or unfavorable.

\subsection{Conclusions}

According to the findings of this study, the majority of married teachers have healthy self-esteem and good marital adjustment. The study concludes that there is a non-significant extremely low positive association between married teachers' self-esteem and marital adjustment, showing that self-esteem is not a significant determinant of marital adjustment of teachers in Anambra State secondary schools.

\subsection{Recommendations}

The following recommendations were made based on the findings:

1. The school administration and school guidance counsellors should work together to ensure that instructors maintain and sustain a positive, healthy self-esteem.

2. School Guidance Counsellors should organise guidance and counselling programmes for married instructors who are not well-adjusted in their marriage. Building good self-esteem for marital satisfaction is one of these techniques.

\section{REFERENCES}

1. Erol, R. Y., \& Orth, U. (2013). Actor and partner effects of self-esteem on relationship satisfaction and the mediating role of secure attachment between the partners. Journal of Research in Personality, 47(1), 26-35. 
2. http://dx.doi.org/10.1016/j.jrp.2012.11.003

3. Farid, M.F., \& Akhtar, M. (2013). Self-Esteem of secondary school students of Pakistan. Middle East Journal of Scientific Research, 14(10), 1325-1330.

4. Jaisri, M. \&Joseph, M.I. (2013). Marital Adjustment and Emotional Maturity among Dualcareer Couples. Guru Journal of Behavioural and Social Sciences, 1(2), 77-84.

5. Johnson, M. D., \& Galambos, N. L. (2014). Paths to intimate relationship quaity from parent-adolescent relations and mental health. Journal of Marriage and Family, 76, 145-160.

6. Muraru, A.A. \& Turliuc, M.N. (2013). Familyof-origin, romantic attachment, and marital adjustment: A path analysis model. Procedia Social and Behavioral Sciences, 33, 90 - 94. doi:10.1016/j.sbspro.2012.01.

7. Onabamiro, A. A., Owoyele, J. W., Elijah, A.O. (2017). Three-factor predictors of marital adjustment among couples in Abeokuta Metropolis, Ogun State, Nigeria. Universal Journal of Psychology 5(5), 225-230.

8. Oprisan, E., \& Cristea, D. (2012). A few variables of influence in the concept of marital satisfaction. Procedia-Social and Behavioural Sciences, $\quad 33, \quad 468-472$. http://dx.doi.org/10.1016/j.sbspro.2012.01.165

9. Sciangula, A., \& Morry, M. M. (2009). Selfesteem and perceived regard: How I see myself affects my relationship satisfaction. The Journal of Social Psychology, 149, 143-158.

10. Schaffhuser, K., Wagner, J., Ludtke, O., \& Allemand, M. (2014). Dyadic longitudinal interplay between personality and relationship satisfaction: A focus on neuroticism and selfesteem. Journal of Research in Personality, 53, 124-133.

11. Sinha (2016). Adjustment of married women in relation to age and job status. International Journal of Scientific and Research Publications, 6(1), 42-45.

12. Spanier, G., \& Cole, C. (1976). Toward clarification and investigation of marital adjustment. International Journal of Sociology of the Family, 6, 121-146.

13. Vanover, B. (2016). Important factors in marital success and satisfaction: marriage counsellors' perspectives. Clinical Research Papers. Retrieved from https://sophia.stkate.edu/cgi/viewcontent.

14. Zandipour,T., Momeni, J.M. (2011). A Study on the relationship between marital satisfaction and job satisfaction among employees of sewage water company in Tehran. Quarterly Journal of Career \& Organizational Counselling, 3(7), 113-29. 